Original Article

\title{
Novel ceramic matrix composites with tungsten and molybdenum fiber reinforcement
}

\author{
Bernd Mainzer $^{\mathrm{a}}$, Chaorong Lin ${ }^{\mathrm{b}, \mathrm{c}}$, Martin Frieß ${ }^{\mathrm{a}}$, Ralf Riedel ${ }^{\mathrm{b}, \mathrm{c}}$, Johann Riesch ${ }^{\mathrm{d}}$, \\ Alexander Feichtmayer ${ }^{\mathrm{d}, \mathrm{e}}$, Maximilian Fuhr ${ }^{\mathrm{d}, \mathrm{f}}$, Jürgen Almanstötter ${ }^{\mathrm{g}}$, Dietmar Koch ${ }^{\mathrm{a}}$ \\ a Deutsches Zentrum für Luft- und Raumfahrt e.V., Institut für Bauweisen und Strukturtechnologie, Pfaffenwaldring 38-40, 70569 Stuttgart, Germany \\ ${ }^{\mathrm{b}}$ Technische Universität Darmstadt, Fachbereich Material- und Geowissenschaften, Fachgebiet Disperse Feststoffe, NPU-TU Darmstadt Joint International Research \\ Laboratory of Ultrahigh Ceramic Matrix Composites, Otto-Berndt-Str. 3, D-64287 Darmstadt, Germany \\ ${ }^{\mathrm{c}}$ Science and Technology on Thermostructural Composite Materials Laboratory, Northwestern Polytechnical University, Xi'an, 710072, PR China \\ ${ }^{\mathrm{d}}$ Max-Planck-Institut für Plasmaphysik, Boltzmannstr. 2, 85748 Garching, Germany \\ e Technische Universität München, Fakultät für Maschinenwesen, Boltzmannstr. 15, 85748 Garching, Germany \\ ${ }^{\mathrm{f}}$ Friedrich-Alexander-Universität Erlangen-Nürnberg, Department Werkstoffwissenschaften, Faculty of Engineering, Martensstr. 5, 91058 Erlangen, Germany \\ ${ }^{g}$ OSRAM GmbH, AM Development Metal (AM MFPD PRE-PLM DMET), Mittelstetter Weg 2, 86830 Schwabmünchen, Germany
}

A R T I C L E IN F O

\section{Keywords:}

Tungsten

Molybdenum

$\mathrm{SiCN}$

CMC

Polysilazane

PIP

\begin{abstract}
A B S T R A C T
Ceramic matrix composites usually utilize carbon or ceramic fibers as reinforcements. However, such fibers often expose a low ductility during failure. In this work, we follow the idea of a reinforcement concept of a ceramic matrix reinforced by refractory metal fibers to reach pseudo ductile behavior during failure. Tungsten and molybdenum fibers were chosen as reinforcement in SiCN ceramic matrix composites manufactured by polymer infiltration and pyrolysis process. The composites were investigated with respect to microstructure, flexural- and tensile strength. The single fiber strengths for both tungsten and molybdenum were investigated and compared to the strength of the composites. Tensile strengths of 206 and $156 \mathrm{MPa}$ as well as bending strengths of 427 and $312 \mathrm{MPa}$ were achieved for $\mathrm{W} / \mathrm{SiCN}$ and Mo/SiCN composites, respectively. The $\mathrm{W}$ fiber became brittle across the entire cross section, while the Mo fiber showed a superficial, brittle reaction zone but kept ductile on the inside.
\end{abstract}

\section{Introduction}

The application of ceramic matrix composites (CMCs) is highly dependent from the chosen fiber. Carbon fiber reinforced CMCs, such as $\mathrm{C} / \mathrm{SiC}$ can be used for short time applications such as nozzles or thermal protection systems for aerospace vehicles [1-3]. For long time applications in high temperature environments silicon carbide fibers are utilized in SiC/SiC CMCs. They have found application in jet engines and are of high interest for next generation nuclear reactors [4-8]. Since the damage tolerance of CMCs is highly dependent from the chosen fiber, the utilization of highly ductile metallic fibers should be very attractive, changing the brittle behavior of ceramics towards a damage tolerant pseudo ductile fracture behavior.

Tungsten and molybdenum are refractory metals with high melting points and high corrosion resistance. Tungsten fibers in particular exhibit high tensile strength and a pronounced ductility and therefore recently become more attractive to be used in high performance composites [9]. They are mass-produced especially for the application as filament in high performance automotive headlights by a powder-metallurgical processing route followed by rolling, swaging and wire drawing [10]. This technique allows different fiber diameters and a tailored composition. Recently, Mileiko et al. successfully manufactured molybdenum fiber reinforced oxide matrix composites [11]. Since tungsten and molybdenum exhibit low thermal expansion coefficients (4.5*10 $10^{-6} \mathrm{~K}^{-1}$ and $4.8^{*} 10^{-6} \mathrm{~K}^{-1}$ at $25^{\circ} \mathrm{C}$ ) [12], such fibers should be of particular interest for the reinforcement of non-oxide ceramics which exhibit low values, too. However, no report can be found about metal fiber reinforced CMCs.

\section{Experimental}

Two different types of metal wires, namely tungsten and molybdenum wires (Osram $\mathrm{GmbH}$, Germany), denoted as fibers in the following, were chosen as fiber reinforcement. Both fibers contain nano-dispersed potassium precipitations, which stabilize the microstructure at high temperatures against recrystallization and grain growth [10]. The tungsten and molybdenum fibers contained $70-80 \mathrm{ppm}$ and $150-200 \mathrm{ppm}$ potassium, respectively. The tungsten fiber had a diameter of $150 \mu \mathrm{m}$ (type BSD-OG-102045280100), the molybdenum fiber had a diameter of $200 \mu \mathrm{m}$ (type MOAB6144601XX42). In the first section tensile test results of the fibers themselves are reported to allow benchmarking of the fiber 
effectiveness in the composite. This was done by the calculation of the fiber strength utilization. The tensile tests were performed with a universal testing machine (TIRA Test 2820) equipped with a $200 \mathrm{~N}$ range load cell at room temperature. For the $\mathrm{W}$ fibers the displacement was measured by the cross head displacement corrected by the machine stiffness. For the Mo fibers the displacement was measured using a contactless optical measurement system as described in [13]. The fiber ends were embedded into a two component epoxy glue (UHU Plus Endfest 300). The cross-section in the embedded area is enlarged and thus the probability of fracture in this area is reduced. The measuring length for the $\mathrm{W}$ fibers was defined by the fiber length between the epoxy embedding which was between 25 and $30 \mathrm{~mm}$. For the Mo fibers it was defined by the setting of the reference points of the optical measurements system to be $30 \mathrm{~mm}$. The tensile tests were performed in a displacement controlled mode with a constant cross-head speed of $5 \mu \mathrm{m} / \mathrm{s}$. The fracture surface of all samples was investigated by optical microscopy and for selected samples using a scanning electron microscope (FEI Helios NanoLab 600, USA). As a measure for deformation, the reduced diameter was determined for selected fiber types using the SEM images.

Using these fibers, unidirectional (UD) fiber reinforced composites were manufactured by means of polymer infiltration and pyrolysis (PIP). As matrix precursor, a low viscosity polysilazane, namely poly (methylvinyl)silazane (PSZ10, Clariant SE, Germany), was chosen. The UD preforms were created via filament winding on graphite mandrels. The winding was performed with a winding angle of $\pm 0.38^{\circ}$. A total of 8 PIP cycles were performed with a mixture of the polysilazane and $1 \mathrm{wt} .-\%$ of dicumylperoxide. The pyrolysis was performed at $1300{ }^{\circ} \mathrm{C}$ at a pressure of 1 bar in a nitrogen atmosphere. The manufacturing process is explained in more detail elsewhere [14]. Each mandrel yielded in two $125 \times 125 \mathrm{~mm}^{2}$ plates which were grinded until a thickness of $3 \mathrm{~mm}$ was reached with a flat grinding machine (Profitline ZB 64, Ziersch \& Baltrusch GmbH, Germany) with a diamond grinding wheel and a diamond grit size of D181. Afterwards, the plates were cut into samples of $120 \times 7 \times 3 \mathrm{~mm}^{3}$ for tensile and four-point bending tests. The density and open porosity were determined by Archimedes method (according to DIN EN 993-1). The fiber volume content was calculated by assuming the matrix density to be $2.30 \mathrm{~g} / \mathrm{cm}^{3}$ [14] and in consideration of the composite density and open porosity. All mechanical tests were performed in a universal testing machine at room temperature (ZwickRoell GmbH \& Co. KG, Germany). The four-point test setup had a support span of $85 \mathrm{~mm}$ and a loading span of $20 \mathrm{~mm}$. The test speed was $1 \mathrm{~mm} / \mathrm{min}$. For the tensile setup a test speed of $10 \mathrm{~mm} / \mathrm{min}$ was chosen. A total of five samples was utilized for each test. The Young's modulus was determined by using strain gauges. The microstructures were investigated using a scanning electron microscope (Zeiss Ultra Plus, Carl Zeiss Microscopy GmbH, Germany) and EDS (XMax20, Oxford Instruments, Germany). Phase analysis was performed by X-ray diffraction using a 2Theta-goniometer (D8 Advance, Bruker AXS, Germany) with $\mathrm{Cu} \mathrm{K}_{\alpha}$ radiation $(154.060 \mathrm{pm})$ with a step size of $0.05^{\circ}$ and $90 \mathrm{~s}$ time/step in the range of $20^{\circ}<2 \theta<70^{\circ}$.

\section{Results and discussion}

In general, Mo and $\mathrm{W}$ fibers show similar tensile behavior. Both fibers exhibit prominent necking. In Fig. 1a and b SEM images of the typical fracture appearance are shown. The inserts show a higher magnification of the center of the two fibers. Polished cross-sections of the two fibers exhibit a homogenous microstructure with elongated grains in the longitudinal direction of the fibers (Fig. 1c and d). This grain morphology is due to the manufacturing process by rolling and wire drawing. In Fig. 2a typical stress-strain curves are demonstrated for the two fiber materials. After linear elastic loading, strain hardening follows before the maximum load is reached within a region with very little stress change. A larger load drop leads to the final fracture. Whereas the characteristics are very similar for both materials the absolute values are different. In Table 1 the properties of both fiber types are summarized. The $\mathrm{W}$ and Mo values were obtained as the mean values of 9 and 23 tests, respectively. It has to be taken into account that due to the different methods of displacement measurement the comparability of the fracture strain values is restricted. This is a typical problem in the testing of thin wire as can be seen in the variation of fracture strain between $1 \%$ and $3 \%[15,16]$ and this paper which all tested the nominal same wire.

The two types of fibers were successfully wound on graphite mandrels. In this process a damaging of the fibers was not detected. After 8 PIP cycles, the resulting fiber volume content was 30 and $24 \%$ for W/ $\mathrm{SiCN}$ and Mo/SiCN, respectively. The open porosity of the W/SiCN was $6.9 \%$, that of its molybdenum counterpart $10.1 \%$. The surface of the $\mathrm{W} /$ $\mathrm{SiCN}$ appeared smoother, probably due to the thinner fiber diameter. The mechanical properties were determined by means of tensile tests and four-point bending. In Fig. $2 \mathrm{~b}$ and $\mathrm{c}$, the corresponding stress-strain curves are shown. Depending on the chosen fiber, considerable different mechanical properties were achieved. It is notable that the composites show a strong variation in strength and fracture strain. In comparison, the $\mathrm{W} / \mathrm{SiCN}$ composites revealed a brittle fracture behavior with low fracture strain.

It was detected that there is a strong correlation between the strength as well as the Young's modulus of the composite and the type of fiber. The results are summarized in Table 2 . The highest values were achieved with the tungsten fibers. The W/SiCN composite exhibited an average tensile strength of $206 \mathrm{MPa}$, while that of the Mo/SiCN composite was analyzed to $156 \mathrm{MPa}$. The bending strength was 427 and $312 \mathrm{MPa}$, respectively. The Mo/SiCN had lower Young's moduli than the $\mathrm{W} / \mathrm{SiCN}$. These values are consistent with the values of the single fibers. The mechanical properties of a pure PSZ10 derived SiCN ceramic has not been investigated so far. Nevertheless, another polyvinylsilazane derived SiCN has been investigated by Nishimura et al. They received a bending strength of $118 \mathrm{MPa}$ and a Young's modulus of $105 \mathrm{GPa}$ [18]. In consequence, the matrix can be seen as a reason why the strengths and Young's moduli of the composites are much lower than the values of the pure fibers. Apart from this, the two composites displayed a completely different fracture behavior. The average tensile fracture strain of $\mathrm{Mo} / \mathrm{SiCN}$ was $0.16 \%$, the bending fracture strain was $2.02 \%$. The fracture strain of $\mathrm{W} / \mathrm{SiCN}$ was considerably lower, especially in the bending tests. The stress-strain curves of W/SiCN are comparable to unreinforced, monolithic ceramics [19]. In comparison, the $\mathrm{Mo} / \mathrm{SiCN}$ displayed a pronounced pseudo ductile behavior, comparable to that of the single fiber tensile tests. After linear elastic loading, strain hardening follows.

In order to explain the mechanical properties of the two composites, the microstructures were investigated by means of SEM, EDS and XRD (Fig. 3 and 4). The SiCN matrix of both composites was well densified with a good attachment towards the fibers. EDS mappings showed that the interfaces between the single PIP cycles as well as between fibers and matrix exhibit oxygen, while the rest of the SiCN matrix is rather free of oxygen. At the PIP- and fiber/matrix interfaces, oxygen concentrations of approximately 5-10 and 20 at.-\% were detected in form of X-ray amorphous SiCNO. It is assumed that this finding is due to the handling of the CMCs in air. The pyrolysis temperature of the polysilazane matrix at $1300^{\circ} \mathrm{C}$ was probably too low to prevent the SiCN surfaces sufficiently from hydrolysis [14]. The fractured surfaces of W/ $\mathrm{SiCN}$ displayed a brittle fracture behavior without fiber pullout or necking. This is in good agreement to the mechanical tests. At the W/ $\mathrm{SiCN}$ interface, the formation of an additional phase was detected, which was confirmed as WC by EDS and XRD (Fig. 3f). As the matrix contains carbon, a reaction of the matrix with the fiber is possible. This could have occurred either by diffusion of carbon or by the formation of volatile species during pyrolysis of the polysilazane, such as $\mathrm{CH}_{4}$ and a subsequent reaction with the fiber surface. Besides these formed small grains of WC, no further phases were detected. The SiCN matrix was Xray amorphous at the chosen pyrolysis temperature. Higher 

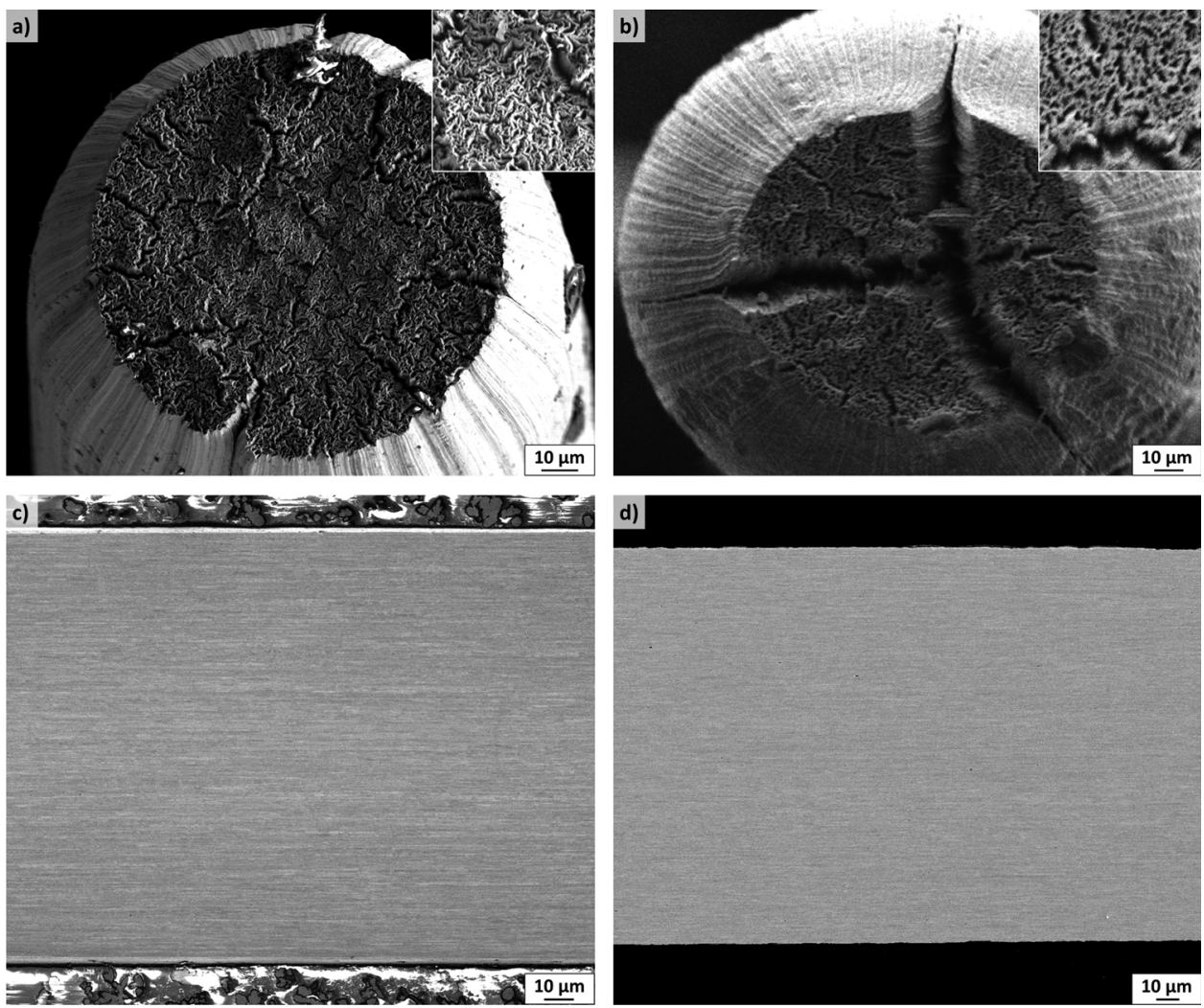

Fig. 1. SEM images of both fibers: a) necking of the tungsten fiber [13]; b) necking of the molybdenum fiber; c) polished cross section of the tungsten fiber; d) polished cross section of the molybdenum fiber.

temperatures (beyond $1400{ }^{\circ} \mathrm{C}$ ) would lead to the formation of $\mathrm{Si}_{3} \mathrm{~N}_{4}$, $\mathrm{SiC}$ and excess carbon [20].

The failure mechanism of the tungsten fibers is pure brittle fracture, as it can be clearly seen in Fig. 3a, b and c. The reason for this behavior in our composite can be derived from investigations, which show that oxygen and carbon contents above 0.02 at.- $\%$ increase the ductile-to brittle transition temperature (DBTT) of tungsten significantly above room temperature [21]. A similar effect of both elements was observed for $\mathrm{W}$ fibers at which carbon seems to be more detrimental. In the $\mathrm{W}$ fiber the carbon amounts needed for embrittlement are in the range of several $10 \mathrm{ppm}$ [22]. In the fibers, carbon leads to embrittlement due to the formation of carbides both on the grain boundaries and within the grains, detectable in TEM studies [23].The carbides at the surface of the wire are a clear indication that sufficient carbon was available but the carbides are not the primary reason for the embrittlement. The carbides throughout the wire leading to the embrittlement are so small that they are not visible both in SEM and EDS analysis.

Fractured surfaces and polished cross sections of the Mo/SiCN composite are presented in Fig. 4. In contrast to W/SiCN the Mo/SiCN exhibited fiber pullout. It was detected, that the Mo fibers had a shelllike reaction zone on the surface. The fiber pullout of the Mo fibers occurred at the shell/matrix interface. Fig. 4b shows a gap between reacted shell and unreacted core due to necking of the unreacted Mo fiber. This necking is comparable to that of as-received fibers (Fig. 1). The W/SiCN in comparison exhibited no such effects. High magnification images of the center of both fibers in the composites (Figs. $3 \mathrm{c}$ and 4c) clearly reveal that the center of the $W$ fiber shows a brittle fracture behavior, while the Mo fiber shows a ductile behavior. The fracture surface of Mo is similar to that of the as-received fibers.

The shell was investigated in more detail by EDS. Accordingly, the shell is comprised of molybdenum based phases. The diffractogram of $\mathrm{Mo} / \mathrm{SiCN}$ (Fig. 4f) shows a composition of metallic molybdenum as well as $\mathrm{Mo}_{2} \mathrm{C}$ and $\mathrm{Mo}_{5} \mathrm{Si}_{3}$. Since the matrix consists of carbon and silicon, it is likely that the matrix is the source for the analyzed degradation. The matrix itself is X-ray amorphous, similar to the W/SiCN composite.

In contrast to tungsten, already small amounts ( $>20 \mathrm{ppm}$ ) of additional carbon are known to remarkably improve the ductility of molybdenum [24]. This is in accordance to our observation of a pronounced ductility during necking of the Mo fiber core at room temperature. We assume that the formation of brittle molybdenum carbide and silicide is the reason for the shown variation of the mechanical properties of Mo/SiCN.

Although Mo and W are both refractory metals with similar chemistry, they exhibited a different reactivity with the SiCN matrix. The pyrolysis temperature was at $1300^{\circ} \mathrm{C}$. In order to investigate the effect of temperature on the reactivity, $\mathrm{W} / \mathrm{SiCN}$ was pyrolyzed at $1500^{\circ} \mathrm{C}$. This resulted in the formation of $\mathrm{W}_{2} \mathrm{C}$, like the $\mathrm{Mo}_{2} \mathrm{C}$ in the $\mathrm{Mo} / \mathrm{SiCN}$ composite, and $\alpha-\mathrm{Si}_{3} \mathrm{~N}_{4}$. Tungsten silicides were not detected. In the case of $\mathrm{Mo} / \mathrm{SiCN}$, pyrolyzed at $1500{ }^{\circ} \mathrm{C}$, besides $\mathrm{Mo}_{2} \mathrm{C}, \mathrm{Mo}_{5} \mathrm{Si}_{3}$ and $\mathrm{Mo}_{3} \mathrm{Si}$ no $\alpha-\mathrm{Si}_{3} \mathrm{~N}_{4}$ was detected. These findings will be described in detail in a further publication.

Thermodynamics were calculated using the HSC Chemistry code [25]. Within this framework the possible reactions of $\mathrm{W}$ and Mo with $\mathrm{SiC}$ and $\mathrm{Si}_{3} \mathrm{~N}_{4}$ at pyrolysis temperatures were evaluated using the standard Gibbs energy minimization method. From these calculations, we conclude that molybdenum prefers the formation of molybdenum silicide $\mathrm{Mo}_{5} \mathrm{Si}_{3}$ besides $\mathrm{Mo}_{2} \mathrm{C}$, while tungsten prefers the formation of tungsten carbide WC (Fig. 5).

Since the tungsten fibers exhibited only a minor reactivity to the SiCN matrix, a protective tungsten coating on molybdenum fibers could help to achieve Mo/SiCN composites with fully ductile fibers and improved mechanical properties. On the other hand, protective coatings on the tungsten fiber could prevent the embrittlement and enable $\mathrm{W} /$ $\mathrm{SiCN}$ composites with fully ductile fibers. A possible coating could be $\mathrm{Er}_{2} \mathrm{O}_{3}$ which was successfully applied in tungsten fiber-reinforced tungsten composites [26]. 

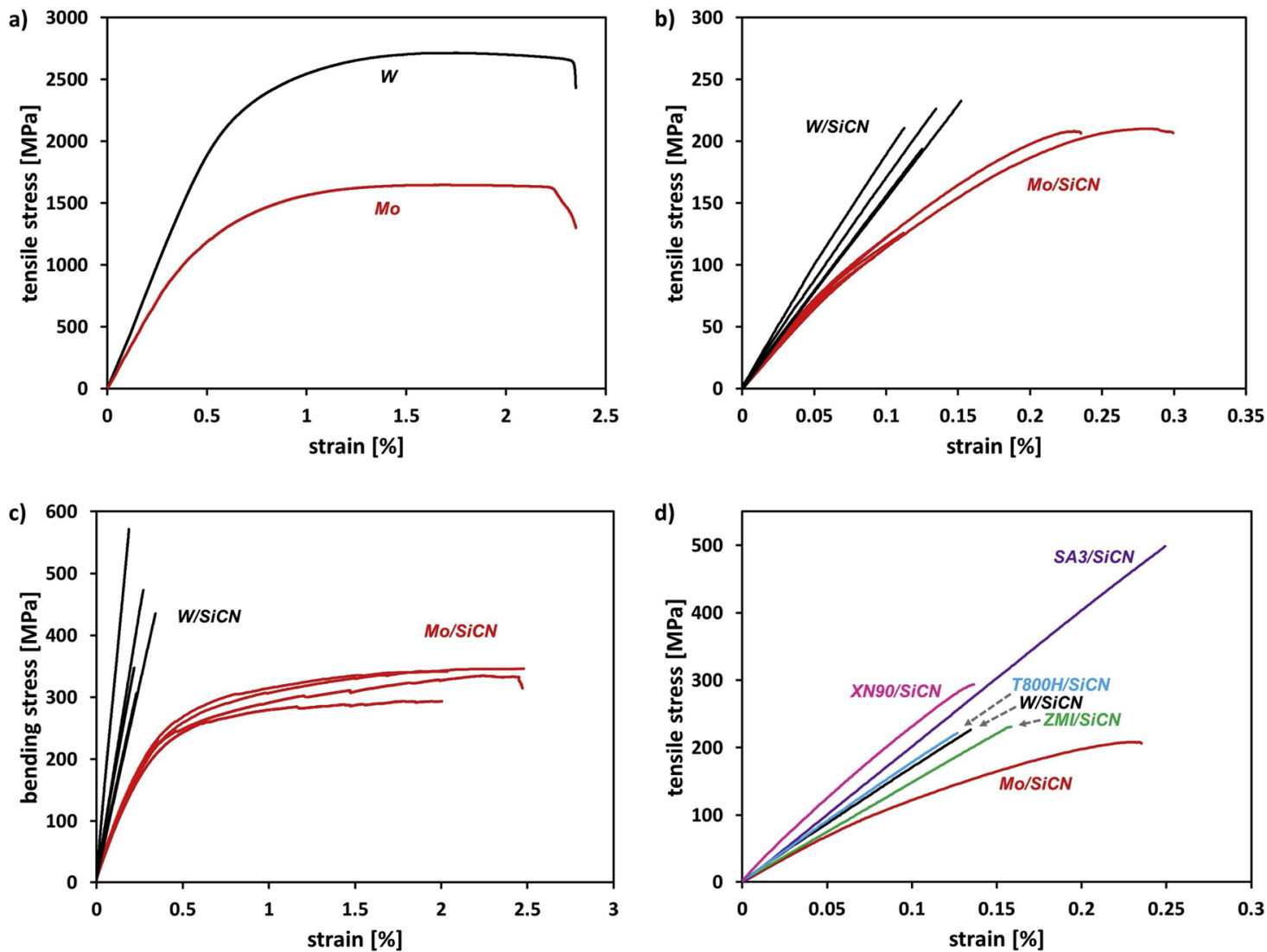

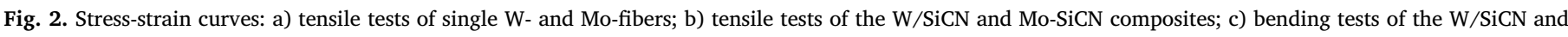

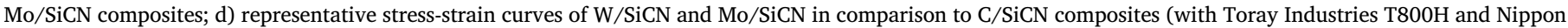
Graphite Fiber XN90 fibers) and SiC/SiCN composites (with Ube Industries Tyranno ZMI and SA3 fibers) [14].

Table 1

Properties of the utilized W and Mo fibers.

\begin{tabular}{llll}
\hline Fiber type & & $\begin{array}{l}\text { Tungsten } \\
\text { BSD-OG-102045280100 }\end{array}$ & $\begin{array}{l}\text { Molybdenum } \\
\text { MOA-B6144601XX42 }\end{array}$ \\
\hline Manufacturer & & Osram & Osram \\
Diameter & $\mu \mathrm{m}$ & 150 & 200 \\
Yield strength Rp0.02 & $\mathrm{MPa}$ & $1855 \pm 18$ & $1207 \pm 5$ \\
Ultimate strength $\mathrm{R}_{\mathrm{m}}$ & $\mathrm{MPa}$ & $2780 \pm 27$ & $1647 \pm 1$ \\
Young's modulus & $\mathrm{GPa}$ & $(400)^{*}$ & $287 \pm 2$ \\
Fracture strain & $\%$ & $1,85 \pm 0,05$ & $1.9 \pm 0.1$ \\
Reduction in area & $\%$ & $38,5 \pm 0,7$ & $70.2 \pm 0.2$ \\
Potassium content & $\mathrm{ppm}$ & $70-80$ & $150-200$ \\
\hline
\end{tabular}

* To allow comparability, the individual measurements of the $\mathrm{W}$ fiber were normalized to a Young's modulus of $400 \mathrm{GPa}$ typical for W materials [17].

Table 2

Physical and mechanical properties of the manufactured W/SiCN and Mo/SiCN composites.

\begin{tabular}{|c|c|c|c|}
\hline \multicolumn{2}{|l|}{ Composite type } & \multirow{2}{*}{$\begin{array}{l}\mathrm{W} / \mathrm{SiCN} \\
30\end{array}$} & \multirow{2}{*}{$\begin{array}{l}\mathrm{Mo} / \mathrm{SiCN} \\
24\end{array}$} \\
\hline Fiber volume content & $\%$ & & \\
\hline Tensile strength & MPa & $206 \pm 27$ & $156 \pm 50$ \\
\hline Tensile modulus & $\mathrm{GPa}$ & $172 \pm 19$ & $144 \pm 7$ \\
\hline Tensile fracture strain & $\%$ & $0.13 \pm 0.02$ & $0.16 \pm 0.09$ \\
\hline Bending strength & MPa & $427 \pm 105$ & $312 \pm 50$ \\
\hline Bending modulus & $\mathrm{GPa}$ & $193 \pm 89$ & $90 \pm 6$ \\
\hline Bending fracture strain & $\%$ & $0.24 \pm 0.08$ & $2.02 \pm 0.93$ \\
\hline Density & $\mathrm{g} / \mathrm{cm}^{3}$ & 7.72 & 4.44 \\
\hline Open porosity & vol.-\% & 6.9 & 10.1 \\
\hline
\end{tabular}

Fig. 2d shows representative tensile stress strain curves of W/SiCN and $\mathrm{Mo} / \mathrm{SiCN}$ in comparison to carbon fiber and silicon carbide fiber reinforced SiCN composites. The applied carbon fibers were $\mathrm{T} 800 \mathrm{H}$ from Toray Industries and XN90 from Nippon Graphite Fiber. The silicon carbide fibers were Tyranno ZMI and Tyranno SA3, both from Ube Industries. The manufacturing process of the composites was identical [14]. No fiber coatings were applied. The stress-strain curves show, that the $\mathrm{C}$ and $\mathrm{SiC}$ fiber reinforced composites exhibit practically no ductile behavior until failure.

The strength of the XN90/SiCN and especially the SA3/SiCN is higher than the metallic counterparts. Nevertheless, this might be a consequence of the rather low fiber volume contents of the metallic fibers in the composites. For a better comparison of the performance of the different fibers, the fiber strength utilization (FSU) was calculated (Table 3). The formula includes the composite tensile strength $\sigma_{\text {comp }}$, the single fiber tensile strength $\sigma$ fiber and the fiber volume content (FVC) and is calculated as follows:

$F S U=\frac{\sigma c o m p}{\sigma f i b e r \cdot F V C}$

The FSU values for the $\mathrm{W}$ and Mo based composites are calculated to be 24.7 and $39.5 \%$, respectively. These values indicate a rather good performance in comparison to the other fiber reinforced SiCN composites. C/SiCN composites with $\mathrm{T} 800 \mathrm{H}$ and XN90 fibers and the $\mathrm{SiC} / \mathrm{SiCN}$ composites with ZMI and SA3 fibers resulted in FSU values of 8.9, 20.0, 12.6 and $44.2 \%$, respectively [14]. Since the fiber volume contents of $\mathrm{W} / \mathrm{SiCN}$ and $\mathrm{Mo} / \mathrm{SiCN}$ were comparably low, it is very likely that similar contents would significantly increase the composite strength. 

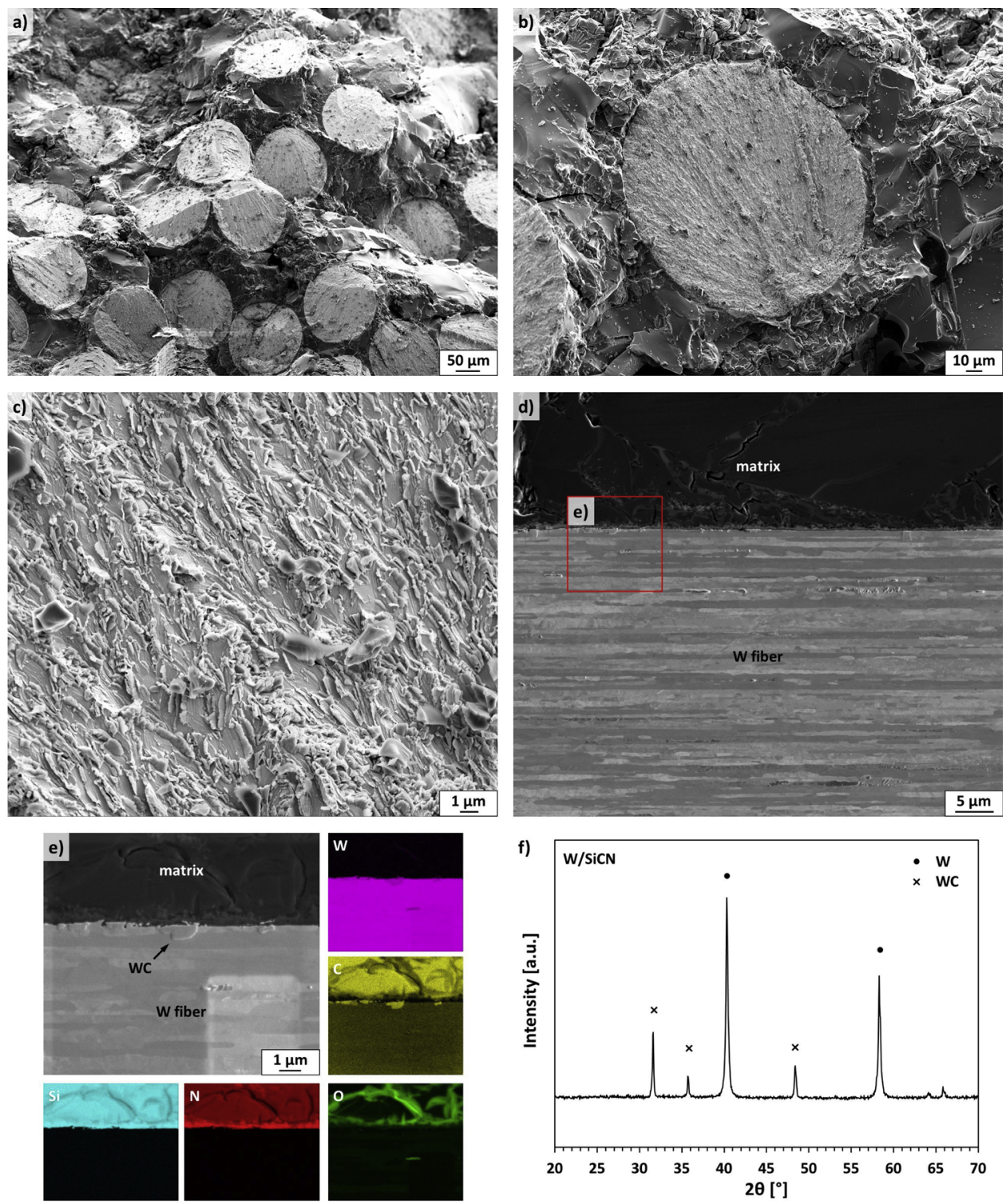

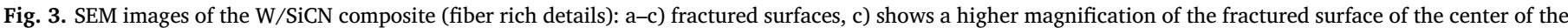
W fiber, $d$ and e) polished cross sections and EDS analysis; $f$ ) diffractogram of a W/SiCN specimen.

\section{Summary and conclusion}

In the present work, unidirectional tungsten and molybdenum fiber reinforced SiCN CMCs were manufactured by means of polymer infiltration and pyrolysis technique. Single fiber tensile tests revealed in an average ultimate strength of $2780 \mathrm{MPa}$ for the tungsten fibers compared to $1647 \mathrm{MPa}$ for molybdenum. The processability of both fibers as reinforcement was good. After 8 PIP cycles porosities of $\leq$ $10 \%$ have been achieved. The $\mathrm{W} / \mathrm{SiCN}$ composite reached an average tensile strength of $206 \mathrm{MPa}$ and a bending strength of $427 \mathrm{MPa}$. SEM investigations showed that the fiber survived the manufacturing, nevertheless a possible inward diffusion of carbon resulted in an increase of the ductile-to brittle transition temperature and thereby in a brittle fracture behavior. The $\mathrm{Mo} / \mathrm{SiCN}$ composite exhibited a lower tensile strength of $156 \mathrm{MPa}$ and a bending strength of $312 \mathrm{MPa}$. In contrast to $\mathrm{W} / \mathrm{SiCN}, \mathrm{Mo} / \mathrm{SiCN}$ showed a ductile fracture behavior with higher fracture strain rates. Although the Mo fiber was partly converted on the outside to $\mathrm{Mo}_{2} \mathrm{C}$ and $\mathrm{Mo}_{5} \mathrm{Si}_{3}$ by the PIP process, the inside kept metallic and ductile. Regarding the fiber strength utilization within the SiCN matrix, both composites performed excellently. For future activities, the metal fibers should be equipped with a coating that prevents from reactions with the SiCN matrix. Based on the presented results we conclude that both, $\mathrm{W}$ and Mo fibers can be considered as alternatives to the currently used $\mathrm{C}$ and $\mathrm{SiC}$ fibers, especially for applications, where the composite weight is not a critical factor. Potential applications for such composites could be in first wall components of future fusion reactors or in parts of stationary gas turbines where both the high strength and the pseudo ductile behavior would be extremely beneficial.

\section{Declaration of Competing Interest}

The authors declare that they have no known competing financial interests or personal relationships that could have appeared to influence the work reported in this paper. 

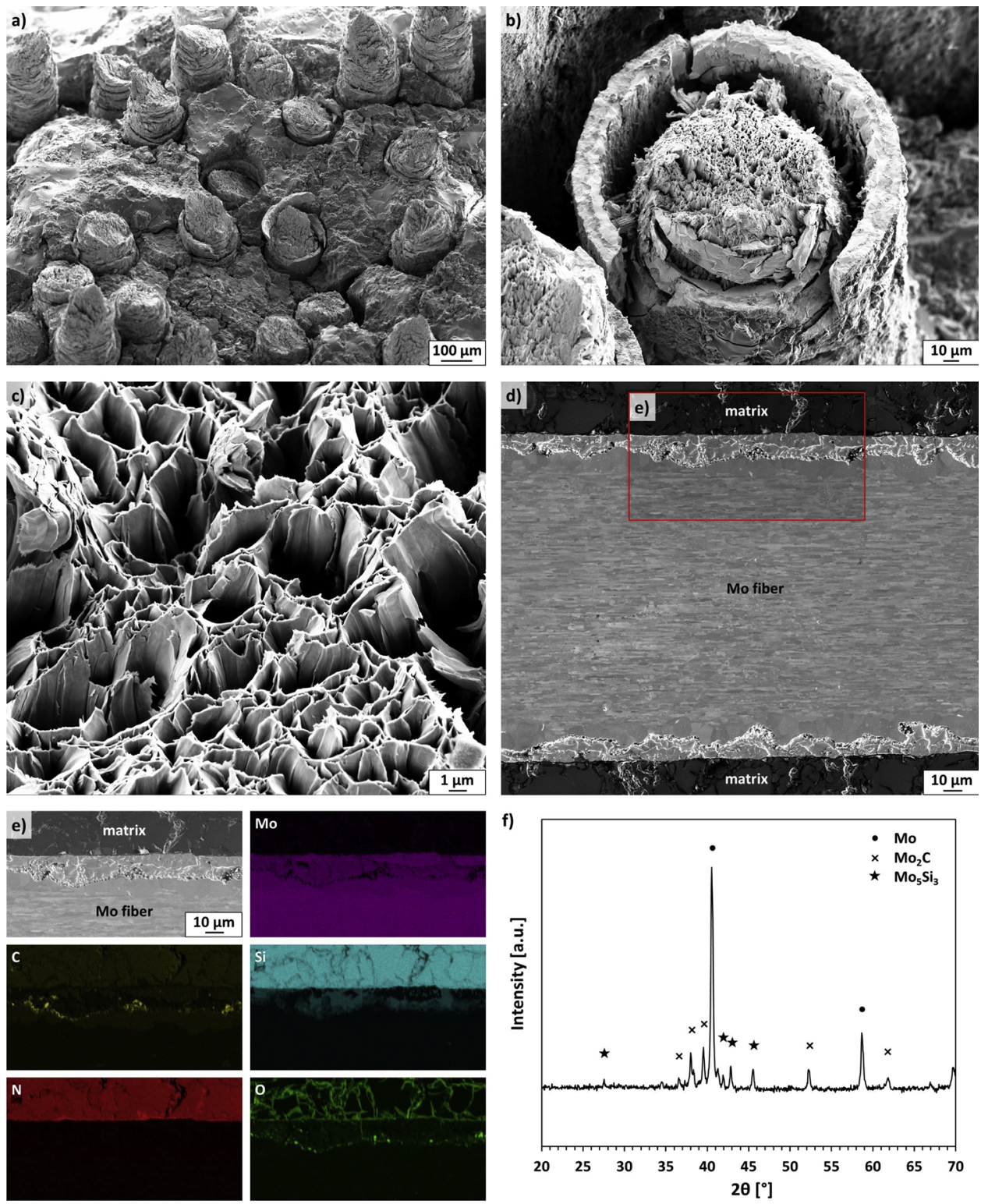

Fig. 4. SEM images of the Mo/SiCN composite (fiber rich details): a-c) fractured surfaces, c) shows a higher magnification of the fractured surface of the center of the Mo fiber, $\mathrm{d}$ and e) polished cross sections and EDS analysis; f) diffractogram of a Mo/SiCN specimen.
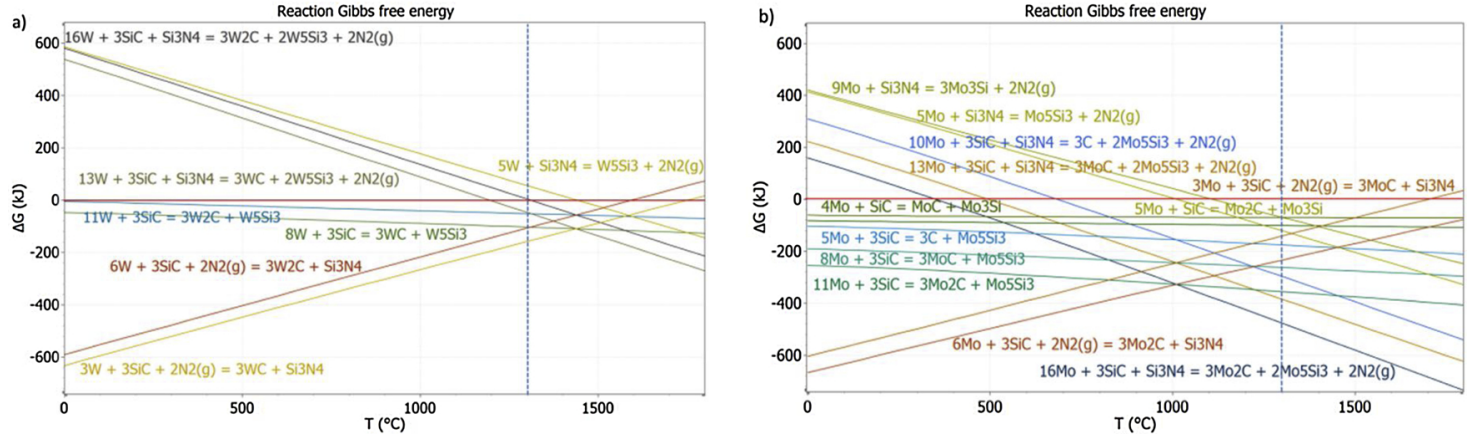

Fig. 5. Thermodynamic calculations of a) $\mathrm{W}$ with $\mathrm{SiC}$ and $\mathrm{Si}_{3} \mathrm{~N}_{4}$ and b) Mo with $\mathrm{SiC}$ and $\mathrm{Si}_{3} \mathrm{~N}_{4}$ (Ellingham diagrams). All reactions with sections $\Delta \mathrm{G}<0$ (below red horizontal line) are viable. The lowest line determines the favorite reaction at a given temperature (here $1300^{\circ} \mathrm{C}$, dashed blue vertical line), which determines for a) $3 \mathrm{~W}+3 \mathrm{SiC}+2 \mathrm{~N}_{2}=3 \mathrm{WC}+\mathrm{Si}_{3} \mathrm{~N}_{4}$ and b) $16 \mathrm{Mo}+3 \mathrm{SiC}+\mathrm{Si}_{3} \mathrm{~N}_{4}=3 \mathrm{Mo}_{2} \mathrm{C}+2 \mathrm{Mo}_{5} \mathrm{Si}_{3}+2 \mathrm{~N}_{2}$ (For interpretation of the references to colour in this figure legend, the reader is referred to the web version of this article). 
Table 3

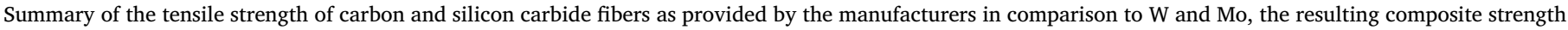
and the calculated fiber strength utilization (FSU).

\begin{tabular}{|c|c|c|c|c|c|c|c|}
\hline \multicolumn{2}{|c|}{ Composite type } & \multirow{2}{*}{$\frac{\mathrm{W} / \mathrm{SiCN}}{2780}$} & \multirow{2}{*}{$\begin{array}{l}\mathrm{Mo} / \mathrm{SiCN} \\
1647\end{array}$} & \multirow{2}{*}{$\begin{array}{l}\text { ZMI/SiCN } \\
3400\end{array}$} & \multirow{2}{*}{$\begin{array}{l}\text { SA3/SiCN } \\
2400\end{array}$} & \multirow{2}{*}{$\begin{array}{l}\mathrm{T} 800 \mathrm{H} / \mathrm{SiCN} \\
5490\end{array}$} & \multirow{2}{*}{$\begin{array}{l}\text { XN90/SiCN } \\
3430\end{array}$} \\
\hline$\sigma_{\text {fiber }}$ & $\mathrm{MPa}$ & & & & & & \\
\hline$\sigma_{\text {comp }}$ & $\mathrm{MPa}$ & $206 \pm 27$ & $156 \pm 50$ & $206 \pm 79$ & $478 \pm 85$ & $224 \pm 40$ & $288 \pm 39$ \\
\hline FVC & $\%$ & 30 & 24 & 48 & 45 & 46 & 42 \\
\hline FSU & $\%$ & 24.7 & 39.5 & 12.6 & 44.2 & 8.9 & 20.0 \\
\hline
\end{tabular}

\section{Acknowledgements}

We want to thank Martin Balden and Katja Hunger from the MaxPlanck-Institut für Plasmaphysik for the EDS measurements. The financial support for the NewAccess project (03EK3544A) by the Bundesministerium für Bildung und Forschung (Germany) is gratefully acknowledged.

\section{References}

[1] F. Breede, S. Hofmann, N. Jain, R. Jemmali, Design, manufacture, and character ization of a carbon fiber-reinforced silicon carbide nozzle extension, Int. J. Appl. Ceram. Technol. 13 (1) (2016) 3-16.

[2] W. Krenkel, Carbon fibre reinforced silicon carbide composites (C/SiC, C/C-SiC), in: N.P. Bansal (Ed.), Handbook of Ceramic Composites, Springer Science + Business Media Inc., New York, USA, 2005, pp. 117-148.

[3] W. Krenkel, F. Berndt, C/C-SiC composites for space applications and advanced friction systems, Mater. Sci. Eng. A 412 (1-2) (2005) 177-181.

[4] G.S. Corman, K.L. Luthra, Silicon Melt Infiltrated Ceramic Composites $\left(\right.$ HiPerComp $\left.^{\mathrm{TM}}\right)$, N.P. Bansal Handbook of Ceramic Composites, Springer US, Boston, USA, 2005, 99-115.

[5] G.S. Corman, K.L. Luthra, J. Jonkowski, J. Mavec, P. Bakke, D. Haught, Melt Infiltrated Ceramic Matrix Composites for Shrouds and Combustor Liners of Advanced Industrial Gas Turbines - Advanced Materials for Advanced Industrial Gas Turbines (AMAIGT) Program Final Report, Department of Energy, United States, 2011.

[6] Y. Katoh, M. Kotani, H. Kishimoto, W. Yang, A. Kohyama, Properties and radiation effects in high-temperature pyrolyzed PIP-SiC/SiC, J. Nucl. Mater. 289 (1) (2001) $42-47$.

[7] C.A. Lewinsohn, C.H. Henager, G.E. Youngblood, R.H. Jones, E. Lara-Curzio, R. Scholz, Failure mechanisms in continuous-fiber ceramic composites in fusion energy environments, J. Nucl. Mater. 289 (1) (2001) 10-15.

[8] M.A. Snead, Y. Katoh, T. Koyanagi, G.P. Singh, SiC/SiC Cladding Materials Properties Handbook, Oak Ridge National Lab. (ORNL), Oak Ridge, TN (United States), Medium: ED; Size: 55 p, 2017.

[9] J. Riesch, J. Almanstötter, J.W. Coenen, M. Fuhr, H. Gietl, Y. Han, T. Höschen, L. Ch, N. Travitzky, P. Zhao, R. Neu, Properties of drawn W wire used as high performance fibre in tungsten fibre-reinforced tungsten composite, IOP Conf. Series: Mater. Sci. Eng. 139 (1) (2016) 012043.

[10] P. Schade, 100years of doped tungsten wire, Int. J. Refract. Metals Hard Mater. 28 (6) (2010) 648-660.

[11] S.T. Mileiko, N.I. Novokhatskaya, N.A. Prokopenko, A.A. Kolchin, A.Y. Mitskevich, V.A. Chumichev, I.V. Novikov, Oxidation resistance and strength of a molybdenum fiber-oxide matrix composite material, Russ. Metall. 2016 (10) (2017) 912-917.

[12] D.R. Lide, W. Haynes, CRC Handbook of Chemistry and Physics : A Ready-reference
Book of Chemical and Physical Data, CRC Press, Boca Raton, USA, 2009.

[13] J. Riesch, A. Feichtmayer, M. Fuhr, J, Almanstötter, J.W. Coenen, H. Gietl, T. Höschen, L. Ch, R. Neu, Tensile behaviour of drawn tungsten wire used in tungsten fibre-reinforced tungsten composites, Phys. Scr. T170 (2017) (2017) 014032.

[14] B. Mainzer, C. Lin, R. Jemmali, M. Frieß, R. Riedel, D. Koch, Characterization and application of a novel low viscosity polysilazane for the manufacture of C- and SiCfiber reinforced SiCN ceramic matrix composites by PIP process, J. Eur. Ceram. Soc. 39 (2) (2019) 212-221.

[15] J. Riesch, Y. Han, J. Almanstötter, J.W. Coenen, T. Höschen, B. Jasper, P. Zhao, C. Linsmeier, R. Neu, Development of tungsten fibre-reinforced tungsten composites towards their use in DEMO—potassium doped tungsten wire, Phys. Scr. T167 (2016) 014006

[16] D. Terentyev, J. Riesch, S. Lebediev, A. Bakaeva, J.W. Coenen, Mechanical properties of as-fabricated and $2300^{\circ} \mathrm{C}$ annealed tungsten wire tested up to $600^{\circ} \mathrm{C}$, Int. J Refract. Metals Hard Mater. 66 (2017) 127-134.

[17] E. Lassner, W.-D. Schubert, Tungsten. Properties, Chemistry, Technology of the Element, Alloys, and Chemical Compounds, 1 ed., Springer Science + Business Media, New York, NY, 1999.

[18] T. Nishimura, R. Haug, J. Bill, G. Thurn, F. Aldinger, Mechanical and thermal properties of Si-C-N material from polyvinylsilazane, J. Mater. Sci. 33 (21) (1998) 5237-5241.

[19] S. Dutta, Fracture toughness and reliability in high-temperature structural ceramics and composites: prospects and challenges for the 21st century, Bull. Mater. Sci. 24 (2) (2001) 117-120.

[20] I.J. Markel, J. Glaser, M. Steinbrück, H.J. Seifert, Experimental and computational analysis of PSZ 10- and PSZ 20-derived Si-C-N ceramics, J. Eur. Ceram. Soc. 39 (2-3) (2019) 195-204.

[21] J.R. Stephens, Effects of Interstitial Impurities on the Low-Temperature Tensile Properties of Tungsten, National Aeronautics and Space Administration, Washington D.C., USA, 1964.

[22] A. Müller, M. Ilg, H. Gietl, T. Höschen, R. Neu, G. Pintsuk, J. Riesch, U. Siefken, J.H. You, The effects of heat treatment at temperatures of $1100{ }^{\circ} \mathrm{C}$ to $1300{ }^{\circ} \mathrm{C}$ on the tensile properties of high-strength drawn tungsten fibres, Nucl. Mater. Energy 16 (2018) 163-167.

[23] Y. Mao, C. Chen, J.W. Coenen, J. Riesch, S. Sistla, J. Almanstötter, A. Terra, Y. Wu, L. Raumann, T. Höschen, H. Gietl, R. Neu, C. Linsmeier, C. Broeckmann, On the nature of carbon embrittlement of tungsten fibers during powder metallurgical processes, Fusion Eng. Des. 145 (2019) 18-22.

[24] Y. Hiraoka, F. Morito, M. Okada, R. Watanabe, Effect of a small amount of additional carbon on the ductility of recrystallized sintered-molybdenum sheet, J. Nucl. Mater. 78 (1) (1978) 192-200.

[25] HSC Chemistry Version 9, Outokumpu Research, OY, Pori, Finland, 2017.

[26] J. Riesch, J.Y. Buffiere, T. Höschen, M. Scheel, C. Linsmeier, J.H. You, Crack bridging in as-fabricated and embrittled tungsten single fibre-reinforced tungsten composites shown by a novel in-situ high energy synchrotron tomography bending test, Nucl. Mater. Energy 15 (2018) 1-12. 